

revista

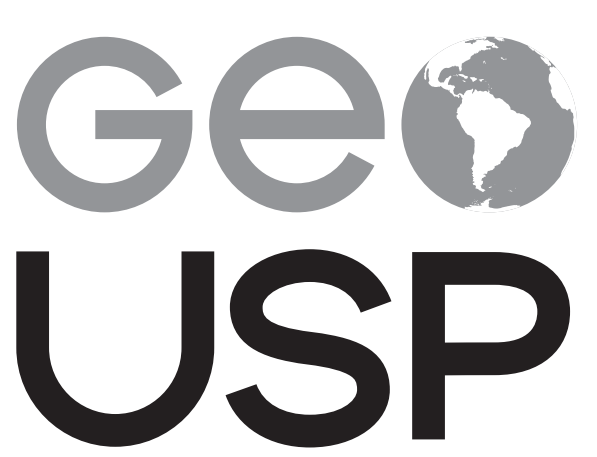

espaço e tempo

Volume $21 \cdot n^{\circ} 2(2017)$
O visível e o invisível:

o sistema

financeiro-corporativo mundial sob o prisma da extraterritorialidade e do binômio legal/ilegal

Lia Osorio Machado

UFRJ

p. $325-340$

Como citar este artigo:

MACHADO, L. O. O visível e o invisível: o sistema financeiro-corporativo mundial sob o prisma da extraterritorialidade e do binômio legal/ilegal. Geousp - Espaço e Tempo (Online), v. 21, n. 2, p. 325-340, mês. 2017. ISSN 2179-0892.

Disponível em: <http://www.revistas.usp.br/geousp/ issue/view/6465> doi: 10.11606/issn.2179-0892. geousp. 2017.136846 .

\section{(c) (i) \$}

Este artigo está licenciado sob a Creative Commons Attribution 4.0 License. 


\title{
O visível e o invisível: o sistema financeiro-corporativo mundial sob o prisma da extraterritorialidade e do binômio legal/ilegal
}

\section{Resumo}

Tomando a abordagem do sistema financeiro-corporativo como um paradigma para compreender o processo de globalização, este artigo discute alguns argumentos favoráveis ou contrários à ideia de que esse processo anuncia o fim do sistema de Estados territoriais soberanos. Propõe que a convivência entre eles é captada pelo conceito de extraterritorialidade, exposto na análise de arranjos espaço-jurisdicionais vinculados ao sistema financeiro-corporativo. Por depender do princípio de soberania territorial, esses arranjos apontam questões mais complexas, entre elas, a disputa entre ordens legais e a manifesta ambiguidade do binômio legal/ilegal nas sociedades atuais.

Palavras-chave: Extraterritorialidade. Sistema financeiro-corporativo. Globalização e estado. Território e lei. Jurisdição e território.

\section{Visible and Invisible: The World Financial-Corporate System from the Perspective of Extraterritoriality and the Legal-Illegal Binary Code}

\begin{abstract}
This article considers the financial-corporate system as one of the paradigms of the globalization process and discusses some of the arguments for and against the idea that this process signals the end of the sovereign territorial state system. We argue that their problematic coexistence is best captured by the concept of extraterritoriality, as exemplified by the analysis of the various types of "jurisdictional-spatial fix" associated to the financial-corporative system. These arrangements are dependent both on jurisdiction and the principle of sovereignty, which suggests that there are more complex issues at stake, foremost the competition between legal orders, and behaviors that resists the distinction between legality and illegality.
\end{abstract}

Keywords: Extraterritoriality. Financial-corporative system. State and globalization. Territory and law. Jurisdiction and territory. 
Um paradoxo do mundo atual, o mundo da "era da informação" e do "ciberespaço" onde é cotidiano o uso de seus suportes e suplementos, como computadores, internet, softwares, celulares, cartões de crédito/débito, caixas eletrônicos, e a visibilidade e a comunicação instantânea se tornaram "objetos" de desejo de uma parte considerável da população, os sistemas que lhes dão sentido e poder são ou se tornam invisíveis. Um desses sistemas, atuante na esfera da circulação do dinheiro, é o sistema financeiro, mais especificamente, o uso do sistema financeiro mundial por corporações transnacionais. Além de atuar em setores tradicionais da economia, essas corporações estão presentes na ciência, na cultura, na tecnologia, nos sistemas de saúde, nos serviços sociais, no setor militar, nos transportes, na mídia, nos jogos de azar, no turismo e assim por diante. Não é, portanto, surpreendente que entre as 100 maiores entidades econômicas do planeta, o número de corporações transnacionais ultrapassa, numa relação de dois para um, o número de países (Hart, 2012).

Para essa invisibilidade contribui o fato de que estamos imersos no milieu (literalmente, meio-lugar) formado por uma extensa e complexa cadeia de mediações e intermediações entre o espaço aparentemente distante e rarefeito onde coabitam conglomerados financeiros e grandes corporações transnacionais, e o espaço da experiência cotidiana dos indivíduos e coletivos, usuários/consumidores finais (em maior ou menor escala) dessa grande engrenagem.

O sistema financeiro-corporativo é um dos paradigmas para a compreensão de um feixe meio solto de processos - conhecidos, presumidos ou prognosticados - que se convencionou chamar de globalização ou mundialização. ${ }^{1} \mathrm{Na}$ versão otimizada do termo globalização, reafirma-se o ideal do universalismo (teológico ou filosófico) da unidade do humano e de uma ordem mundial colaborativa (pela comunicação), não desunida por diferenças nacionais. No entanto, como é sabido, a visão positiva, por vezes abstrata, dos processos de globalização tem sido enunciada principalmente por organizações internacionais (IMF, Banco Mundial, OECD, OMC etc.) em termos de livre comércio e abertura dos mercados nacionais a livre circulação de capitais e da informação. Foi incorporada ao senso comum por imagens como "um mundo sem fronteiras" (que retém a positividade associada ao livre movimento), ou a "porosidade das fronteiras" (associada a negatividade do medo e de seu corolário, as políticas de defesa e segurança).

Esse pacote de propostas e imagens foi seguido por uma considerável literatura sobre a morte iminente dos Estados territoriais nacionais. Os críticos mais radicais dos processos de globalização enfatizam a caducidade dos "capitalismos nacionais", englobados pela economia financeira mundial, e a decadência da política como motor do Estado-nação, sucedida pelo governo/administração do território, crescentemente direcionado para questões de segurança. Mais radicais ainda são os cientistas sociais que afirmam a insustentabilidade da forma "Estado", clamando por alternativas, outras possibilidades de governança abertas a maior participação popular: a partir de conceitos fortes como descolonialidade e desconexão, eles propõem a rejeição da forma Estado, por ser ela uma dimensão fundamental da "matriz colonial de poder" (Quijano, 2014; Mignolo, 2012, 2014).

1 Autores como Jean-Luc Nancy e Samir Amin distinguem os dois termos, mas, neste artigo, são tomados como equivalentes. 
Existe uma ligação entre o poder crescente do sistema financeiro-corporativo e o enfraquecimento do sistema de Estados territoriais nacionais? O sociólogo catalão Manuel Castells, por exemplo, em sua obra de três volumes sobre a A era da informação (1998) enfatiza que, graças aos avanços tecnológicos, o poder sob a forma do grande capital é fluido, livre de limites e fronteiras territoriais, enquanto a política permanece presa ao terreno, sujeita aos limites impostos por seu caráter local. Posto nestes termos, seria essa a emergência de uma nova assimetria entre a "natureza extraterritorial do poder e a permanência territorial da 'vida plena' de uma localidade" (Bauman, 1999)?

É certo que o poder atribuído ao capital financeiro resulta da imensa quantidade de "dinheiro-bit de informação" movimentada em tempo real entorno do globo usando algoritmos cada vez mais complexos. No entanto, o sistema financeiro-corporativo só mostra a real dimensão do seu poder quando atentamos para o fato de que seus efeitos são amplificados pela capacidade (potencial ou efetiva) de integrar, de forma transacional, o social, o político, o econômico, o espacial, o legal e o ilegal numa mesma engrenagem. Para a geografia política e, como veremos, para áreas afins, esse tipo e escala de poder envolve a relação com o território e o territorial, porém sob que condições?

Este artigo examina algumas das condições em que, na atual conformação do sistema financeiro-corporativo, o territorial e o Estado territorial permanecem como referencial. Para começar, o sistema financeiro explora as diferenças entre governos e suas leis, o que permite lucrar com as diferenças regulatórias entre territórios nacionais ("economia da arbitragem"), bem como com os centros de intermediação financeira offshore ${ }^{2}$ e os lugares-refúgio para a evasão fiscal (Machado, 1996). Por sua vez, as corporações transnacionais, alimentadoras e usuárias do sistema financeiro e de seus arranjos espaciais, também dependem do espaço político dos Estados territoriais: é a política.

[...] que concretamente organiza os espaços de liberdade, cidadania, obediência às leis e eficiência institucional. A política estende os espaços de domínio, traça linhas de exclusão, desenha fronteiras internas e externas, determina o centro e as periferias, os "altos" e os "baixos", e articula os espaços de produção e consumo (Galli, 2010, p. 5).

Neste artigo, nos interessa examinar a possibilidade de que uma das condições para a convivência do sistema financeiro-corporativo com os Estados territoriais é captada pelo conceito ou noção de extraterritorial ou extraterritorialidade, entendido como "além do território" ou "fora do território". ${ }^{3}$ Por sua vez, a imaterialidade dos fluxos financeiros

2 termo offshore foi originalmente empregado por companhias petrolíferas para designar a localização de áreas de extração fora do continente. Também foi empregado no período da proibição de consumo de bebidas alcoólicas nos EUA, quando as máfias contrabandeavam bebidas para as ilhas localizadas além do limite das águas territoriais do Estado, ou seja, fora de sua jurisdição, uma prática adotada até hoje por barcos-cassinos dedicados aos jogos de azar.

3 Cameron (2016, p. 139, n. 2) afirma, com razão, que o dinheiro é também "exterritorial" - sem território, e não simplesmente fora do território: é o caso de setores internos ao banco que operam numa sala como se estivessem offshore, isto é, com uma regulação diferente daquela válida para operações no mercado doméstico ao permitir a oferta de serviços para indivíduos e instituições não residentes, como é o caso das IBF, nos EUA. É uma indicação de que o sistema financeiro atingiu outro nível de complexidade, cujo conceito de "território" não se fundamenta exclusivamente nos princípios da geometria euclidiana de superfície plana, contínua (terrestre) e de extensão de superfície (Machado, 1996, p. 62). 
e a materialidade dos Estados territoriais pressupõem a existência de sistemas legais que competem entre si, o que provoca uma crescente ambiguidade do binômio legal/ilegal nas sociedades atuais.

Considerar o sistema financeiro-corporativo como um paradigma da globalização nos termos em que ele se apresenta atualmente se inspira na discussão de Agamben (2009) sobre o status epistemológico do paradigma: para este filósofo político é possível questionar a oposição dicotômica entre o particular e o universal, geralmente considerados inseparáveis dos procedimentos do conhecimento, e considerar o paradigma como uma singularidade, irredutível à dicotomia dos dois termos.

dinheiro, a moeda, os bancos e as finanças estavam presentes em sociedades passadas, assim como a simbiose entre sistema financeiro e corporações multinacionais. Em termos históricos, então, não se trataria de uma singularidade. Mas não se trata da origem, pois, de acordo com o mesmo autor, todo fenômeno é a origem, sua historicidade não residindo nem no diacrônico nem no sincrônico e sim no cruzamento de ambos, de modo a tornar inteligível uma série de fenômenos interligados.

\section{A imagem política do mundo e a condição de extraterritorialidade}

Não é incomum encontrarmos críticas aos tradicionais mapas políticos mundiais por difundirem uma forma de representação abstrata do sistema internacional que reforça a noção de soberania exclusiva, ou seja, as áreas dos estados com seus limites interestatais como zonas de jurisdição mutuamente exclusivas, com isso tornando invisível que as organizações internacionais operam "acima" dos Estados nacionais (ex. Kratochwil, 2011).

A ideia de soberania exclusiva sobre um determinado território é geralmente derivada, ou vista como constituinte, do conjunto de tratados europeus conhecido como o tratado de Vestfália [Westphalia] (1648), elaborado na Europa desde a época dos grandes impérios coloniais até a descolonização no século XX, que legitimou a ideia de uma ordem internacional composta por Estados territoriais relativamente autônomos. No entanto, convém lembrar que os tratados de Vestfália foram elaborados com vistas a sustentar o equilibrio do poder na Europa, uma "região geográfica de estados múltiplos, com desnível entre pequenos e grandes, tendo com o resto do mundo uma relação de utilização, de colonização, de dominação" (Foucault, 2008, p. 400). Desde então e até hoje as condições concretas da ordem internacional - hegemonia e hierarquia - estão com frequência ausentes da legenda dos tradicionais mapas políticos mundiais. Sob a ótica da "matriz colonial de poder" por exemplo, Siba Grovogui (2002) argumenta, entre outras questões, que não existe e não existiu no passado um sistema de soberania uniforme, os regimes de soberania diferem no tempo e diferem segundo as regiões do mundo. Em outras palavras, diferentes regimes de soberania geram relações de qualidade variável entre estados e entre Estados e território.

Mesmo que estejamos cientes de suas limitações, os mapas políticos mundiais constituem um "modelo", com o território definido de forma convencional como a área sob jurisdição de um Estado soberano, a condição para um Estado existir e a forma em que o poder do Estado é espacializado. Sem dúvida é uma definição restritiva de território, insistentemente criticada por vários geógrafos com razão, mas o mapa político mundial permanece como um "modelo" de uma ordem política ativa, mesmo que ambígua em seu conteúdo e funcionamento. 
A despeito da associação entre soberania, território e jurisdição ser um tema recorrente na geografia política, a reabertura relativamente recente das discussões sobre essa associação no campo do direito (não das relações internacionais) abre novas condições de possibilidade para uma mudança no seu entendimento, especificamente no sentido de uma "lei global sem Estado" no campo do direito internacional (Teubner, 1997; Cutler, 1997; Michaels, 2007; Lindahl, 2010). A possibilidade de existir uma "lei global sem Estado" incide diretamente sobre o questionamento da relação entre o sistema financeiro-corporativo, o Estado territorial e a extraterritorialidade.

Tomo como exemplo inicial desse questionamento os guias dos mochileiros da galáxia Fundo Monetário Internacional que estabelecem os critérios de medição dos fluxos de investimentos diretos transnacionais: ${ }^{4}$ The Coordinated Direct Investment Survey Guide (CDIS) - Pre-Publication Draft (IMF, 2015a, 2015b) e a 6a edição do Balance of Payments and International Investment Position Manuel ou BPM6 (IMF, 2009).

Para o BPM6, a residência de uma entidade é um critério básico por se referir a um território econômico:

[...] no sentido mais amplo, o território econômico pode ser qualquer área geográfica ou jurisdição [ênfase adicionada] para os quais estatísticas sejam necessárias; a conexão de entidades a um território econômico em particular é determinada [a partir] de aspectos como presença física e estar sujeito a jurisdição do governo do território (IMF, 2009, p. 50).

Logo adiante, "o conceito mais comum de território econômico é a área sob controle econômico efetivo de um único governo" (IMF, 2009, p. 50), incluindo as zonas [econômicas] especiais. No entanto, segundo o guia:

Outros tipos de território econômico incluem parte de uma economia, regiões, ou o mundo como um todo. Os tipos de territórios econômicos incluem: (a) a área terrestre; (b) o espaço aéreo; (c) as águas territoriais (incluindo áreas sobre as quais jurisdição é exercida sobre direitos de pesca, de combustíveis ou minerais); (d) territórios marítimos, ilhas que pertencem a um território; (e) enclaves territoriais no resto do mundo (IMF, 2009, p. 50, tradução nossa).

Enquanto os tipos de (a) a (d) são facilmente referenciados aos regimes de soberania, talvez por isso dispensando maiores explicações, para o último tipo, enclaves territoriais, muitas palavras foram necessárias, embora o texto permaneça confuso:

[...] são áreas terrestres claramente demarcadas (como embaixadas, consulados, bases militares, estações científicas, escritórios de informação ou imigração, agencias de ajuda, escritórios de representação dos bancos centrais com status

4 Investimento direto é quando uma unidade residente numa economia faz um investimento que the dá controle ou um grau significativo de influência na administração de uma empresa que reside em outra economia (capítulo 2 do CDIS). As unidades [agora consideradas instituições] institucionais podem ser corporações (definidas em termos estatísticos para incluir empresas incorporadas ou não, empresas públicas ou privadas, fundos de investimento, sucursais, unidades residentes nacionais, trustes e outras quase-corporações), instituições sem fins lucrativos, unidades governamentais, organizações internacionais, indivíduos e familias. $\bigcirc$ artigo de Luque, Silber e Zagha (2017) aborda as mudanças que ocorreram no IED na última década ao descrever o caso brasileiro, onde investimentos externos podem consistir apenas na operação especulativa de captar recursos a custos baixos no exterior e aplicar aqui a juros mais altos. Se confirmado por mais análises, não se sustentará a distinção entre IED e hot money que prevalecia na década de 1990 (ver Machado [1996]). 
diplomático) que estão fisicamente localizadas em outros territórios e usadas por governos que são proprietários ou as alugam para propósitos diplomáticos, militares, científicos, ou outros propósitos [ênfase adicionada], com o acordo formal dos governos dos territórios onde as áreas terrestres estão fisicamente localizadas. Essas áreas podem ser compartilhadas com outras organizações, mas as operações precisam ter um alto grau de isenção das leis locais para ser tratadas como enclave. No entanto, operações governamentais totalmente sujeitas às leis da economia hospedeira não são tratadas como enclaves, mas residentes da economia hospedeira (IMF, 2009, p. 50, tradução nossa).

A palavra extraterritorial não é empregada no documento de 371 páginas, exceto quando, ao descrever o status legal de residência de funcionários transfronteiriços (IMF, 2009, p. 186), o guia remete o leitor a citação acima, onde é empregado o termo extraterritorialidade. Na página seguinte, o guia se refere a "zonas especiais" para designar a criação por parte de um governo de uma "zona física ou legal" sob o seu controle [ênfase adicionada] para a qual, até um certo grau, leis separadas são criadas. Os exemplos do FMI são as zonas de livre comércio ou os centros financeiros offshore, por estarem isentos de alguns impostos ou por que neles "outras leis" são aplicadas. À estas zonas, o guia não emprega a palavra extraterritorial, com isso pretendendo manter o sentido literal e clássico de "fora do território" nacional (os exemplos mais conhecidos são as representações diplomáticas e as bases militares).

Operações semânticas desse tipo não são tentativas de mascarar algo impróprio, e sim a expressão de uma dificuldade concreta: conciliar a "regra geral" - a divisão do mundo em Estados territoriais soberanos (representados no FMI), que permite distinguir o que está dentro e o que está fora do território nacional - com o número de "arranjos jurisdicionais" 5 num mesmo território, mas que operam a partir de regras de exceção à regra geral. ${ }^{6}$

\section{Regras de exceção: arranjos espaço-jurisdicionais e sistema financeiro- -corporativo}

Arranjos jurisdicionais são de tipos diversos, porém nos interessa aqueles que para o sistema financeiro-corporativo são "espaços vazios", no sentido de não oferecerem resistência a projetos de instrumentalização movidos pela razão econômico-financeira. É o caso da criação, transformação ou uso de jurisdições para implantar centros financeiros offshore e/ou lugares-

5 A Tax Justice Network (um grupo de pesquisadores e ativistas que advogam por justiça fiscal) descreve uma jurisdição como qualquer território com seu próprio sistema legal, seja esse território independente ou soberano, componente de um Estado federado (ex. Dubai), território dependente além-mar (ex. Ilhas Cayman, Ilha de Man) ou uma zona interna a qual é aplicada um regime legal especial (ex. Labuan na Malásia). Apesar de reconhecer a praticidade dessa descrição, ela simplifica em demasia as questões políticas mais amplas associadas à jurisdição, o que nos leva, neste artigo, a propor o termo "arranjos espaço-jurisdicionais", de modo a destacar a problemática relação entre o sistema financeirocorporativo, o sistema de Estados territoriais soberanos e a extraterritorialidade.

6 A confusão conceitual e analítica do FMI ocorre também no BIS (Bank of International Settlement, o "banco central dos bancos centrais"). Ambas as organizações internacionais não podem evitar a inclusão dos centros financeiros offshore devido a sua importância nos fluxos financeiros globais, porém fazem malabarismos classificatórios para estabelecer diferenças entre eles; a Cidade de Londres, por exemplo, não é categorizada como um centro financeiro offshore, apesar de ser o maior do mundo, como bem explicado no documento produzido pela Câmara dos Comuns da Grã-Bretanha por ocasião da crise financeira de 2007-2008 (House [...], 2008). 
-refúgio para a evasão fiscal. Se essas jurisdições são "ilhas", no sentido geográfico, como de fato o são muitos desses lugares, ou "ilhas" no sentido figurado de excepcionalidade em relação ao sistema interestatal, elas formariam "arquipélagos de exceção", a metáfora utilizada por Franke, Weizman e Weizman (2003) e Weizman (2005) para assinalar a multiplicidade de zonas extraterritoriais - "expressão espacial de Estados de exceção" 7 - onde a soberania dos Estados territoriais é desafiada ou suspensa.

"Ilha" é uma feliz metáfora e imagem de "fora do território", porém, quando se trata do sistema financeiro-corporativo, o problema é que a soberania dos Estados territoriais não foi desafiada ou suspensa: essas "ilhas" ou "zonas" são absolutamente legais do ponto de vista jurisdicional por derivarem do ato soberano de um Estado nacional, com poder, portanto, de criar "exceções" às leis que regem a vida da maior parte das pessoas e corporações no território nacional (como reconhecido pelo IMF [2009]). Por outro lado, há lugares que não são "ilhas de exceção" e sim Estados independentes por direito, o que, aliás, explica o número surpreendente de pequenas ilhas (no sentido geográfico) que se tornaram Estados-nação nas últimas décadas (Bahamas, Vanuatu, Seychelles, Samoa etc.).

Considerando a complexa estruturação desses arranjos espaço-jurisdicionais, 8 é útil delinear, grosso modo, uma tipologia desses arranjos no que se refere aos centros financeiros offshore e paraísos/refúgios fiscais:

(a) colônias residuais de antigos impérios europeus, exemplificados nos "territórios dependentes do além-mar" da Grã-Bretanha (Overseas Dependent Territories): Ilhas Cayman, Ilhas Virgens Britânicas, Bermuda, Gibraltar, Anguilla etc.; e as "dependências da Coroa Britânica" (British Crown Dependencies): ilhas de Guernsey, Man, Jersey no Canal da Mancha; ou as Antilhas Holandesas e Aruba (colônias dos Países Baixos). Acrescentam-se territórios literalmente comprados, como é o caso das Ilhas Virgens Americanas, adquiridas do reino da Dinamarca durante a la Guerra Mundial.

(b) Estados pequenos e microestados, especializados em vários tipos de serviços financeiros offshore, que fornecem seus serviços a não residentes (bancos e outras unidades financeiras, corporações, escritórios de advocacia, indivíduos etc.), não disponíveis para os seus próprios cidadãos. Liechtenstein, por exemplo, que compartilha com a Suíça uma união aduaneira e fortes laços políticos, criou fundações que operam como offshore em seu território, com isenção de impostos aos seus usuários e segredo das transações de corporações, benefícios esses não disponíveis aos residentes, uma diferença de tratamento que se repete em vários pequenos Estados, como a vizinha Suíça, ou o Grão-Ducado de Luxemburgo, um dos governos mais ricos do mundo (35\% do PIB é oriundo do setor financeiro), cujas facilidades financeiras são

7 Weizman (2005) e Franke, Weizman e Weizman (2003) derivam de Giorgio Agamben a expressão "Estado de exceção", título de um livro e um dos conceitos-chave do filósofo, parcialmente inspirado no pensamento político do jurista Carl Schmitt (1888-1985) (ver Agamben [2005]).

8 São arranjos no sentido que David Harvey denomina spatial fix (arranjos espaciais inventados pelo sistema capitalista mundial como forma de sobreviver às sucessivas crises), porém aqui o uso do termo remete aos interstícios do sistema interestatal e à cama de gato que estão se tornando as leis internacionais, ou seja, esses arranjos são jurisdicionais e não só espaciais. É uma concepção diferente daquela de Henry (2012), por exemplo, cujo trabalho apresenta cuidadosas estimativas sobre os valores movimentados pelo mercado offshore-inshore e suas consequências fiscais, mas discorda da "tradicional" associação de offshore com localizações físicas, preferindo destacar o caráter transfronteiriço dos fluxos financeiros. 
aproveitadas também pelo Banco Central Europeu. Um número considerável de microestados são ex-colônias europeias, principalmente da Grã-Bretanha, como é o caso da cidade-Estado de Singapura, que mantém laços financeiros umbilicais com o centro offshore de Londres; as ilhas Bahamas, Samoa, Palau (república em livre associação com os EUA); Seychelles; as ilhas Cook (autogoverno em livre associação com a Nova Zelândia), a pequena república-ilha de Vanuatu no oceano Pacífico; a Malásia que criou o território federal de Labuan como centro offshore para uma série de atividades além da financeira, e assim por diante.

(c) Estados territoriais consolidados e desenvolvedores de uma série de regulamentos e de uma estrutura fiscal complexa (gradual e excepcionalmente instituídos no contexto que se seguiu às duas Guerras Mundiais no século XX, como analisado pelo economista Thomas Piketty). Regulamentos e estrutura fiscal foram, formal e idealmente, concebidos para manter os aparatos de estado em funcionamento e com isso servir e proteger os seus cidadãos (de onde derivaria sua legitimidade). Movidos por uma série de circunstancias políticas, econômicas, tecnológicas, tanto internas quanto externas, os mesmos Estados estabeleceram mecanismos de escape e diferenciação das regras regulatórias e/ou fiscais em algum lugar ou lugares do próprio território nacional. Vários desses Estados, que se apresentam e são vistos como modelos a serem seguidos pelo resto do mundo, incorporaram ao respectivo aparato legal as condições de possibilidade para operações financeiras e preferências fiscais excepcionais, ao criar figuras jurídicas, variáveis de país para país, como, por exemplo, os "estrangeiros não residentes" nos EUA, ou "estrangeiros não domiciliados" na Grã-Bretanha ou na Suíça. Por conseguinte, as "zonas especiais" ou a "zona física ou legal" são extraterritoriais no sentido de operarem segundo regras diferentes daquelas válidas no restante do território nacional embora sob a jurisdição estatal.?

Um dos aspectos geográficos mais interessantes dos arranjos espaço-jurisdicionais, quando instituídos como centros financeiros offshore (CFO) e/ou paraísos fiscais, é o funcionamento em rede: uma parafernália de organizações privadas (bancos, firmas de intermediação financeira, trustes, corporações, fundações, escritórios de contabilidade, consultoria e advocacia etc.) formam conexões quase-orgânicas de alcance global, mesmo quando competem entre si. Sobre essas bases é que foi constituído e se desenvolveu o maior CFO do mundo, a City of London Corporation, que reúne o centro histórico e o setor financeiro da cidade de Londres. Enquanto os serviços de "refúgio fiscal" oferecidos a corporações, firmas e indivíduos não residentes não são recentes, os CFO surgiram em meados da década de 1970 como lugares em que operadores financeiros podiam levantar fundos de não residentes e investir ou emprestar dinheiro para outros não residentes, livres da maioria dos regulamentos e dos impostos (Palan, 2002, 2012). É precisamente a condição de não residente como principal usuário das facilidades oferecidas pelo lugar hospedeiro que deu consistência ao termo offshore. Como Ronen Palan sintetiza no caso da City of London, as transações entre não residentes e em moeda estrangeira (que não a libra esterlina), mediadas por bancos britânicos ou não, são consideradas pelo Banco da Inglaterra como finanças offshore, ou seja, não estão sujeitos às leis regulatórias e a supervisão do Estado-governo britânico.

9 Há uma diversidade de "zonas especiais": áreas de livre comércio, zonas de processamento de exportações, portos e zonas francas, zonas econômicas especiais (as chinesas são as mais conhecidas), porém neste artigo, vale ressaltar, o termo extraterritorial se refere apenas aos centros financeiros offshore e aos refúgios fiscais. 
alcance geográfico da desregulamentação londrina logo se estendeu às colônias residuais e às ex-colônias do seu antigo império espalhadas pelo mundo (ilhas do Canal da Mancha, ilhas Maurício ou Mauritius, Hong Kong, Singapura, Bermuda, ilhas Cayman etc.), ou seja, a City substituiu o império colonial que perdeu por outro, baseado em paraísos fiscais e CFO (Shaxson, $2011^{10}$ apud Hart, 2012).

Se a conexão financeira inicial mais importante de Londres offshore foi com as subsidiárias dos bancos estadunidenses, que estavam sujeitos nos EUA a um ambiente financeiro-bancário estritamente regulado pelo governo, a expansão das operações internacionais das multinacionais americanas a partir da década de 1950 as levou ao desregulamentado mercado financeiro londrino para obter melhores taxas de juros e empréstimos em seus investimentos internacionais. Nas décadas seguintes, bancos alemães e japoneses, investidores institucionais, corporativos e privados, ${ }^{11}$ além de uma imensa quantidade de petrodólares dos países árabes aproveitaram-se dessas facilidades, embora a City, premida por questões políticas internas (a última sendo o Brexit), tenha restringido algumas delas, principalmente no âmbito fiscal.

Uma observação. Recentemente, alguns centros financeiros offshore foram rebatizados de Centro Financeiro Internacional (IFC na sigla em inglês), provavelmente para fugir da má-fama associada ao termo offshore, primeiro por ser a eles atribuído, corretamente aliás, um papel relevante em fuga de capitais, evasão fiscal e operações de lavagem de dinheiro nas últimas décadas, mas principalmente pela visibilidade que adquiriram nas análises imediatamente seguintes a crise financeira de 2007-2008. A substituição de offshore por "internacional" pode ser visto como um movimento de criação de uma nova imagem, sugestiva de um sentido funcional para as operações voltadas para o espaço global, evitando o uso do conceito de extraterritorialidade associado ao termo offshore, e com ele suas implicações políticas para o Estado territorial nacional.

caminho dos Estados Unidos para a desregulamentação tem sido mais tortuoso, mais generoso com as corporações, e mais voltado para a redução ou suspensão de pagamentos de impostos. Mesmo antes da criação dos IBF (1981), direcionado aos investimentos internacionais, o estado de Wyoming no extremo oeste do país, aproveitando-se do regime federativo, aprovou no legislativo estadual (1977) um tipo novo de companhia, as LLC (Limited Liability Company), uma entidade híbrida, na qual, além de certas facilidades fiscais locais, os sócios não são pessoalmente responsáveis pelas dívidas da corporação.

10 SHAXSON, N. Treasure Islands: Tax Havens and the men who stole the world. London: Boldey Head, 2011.

11 O sucesso do CFO londrino foi rapidamente reproduzido no Singapore Asian Currency Market (1968), seguido, menos de duas décadas depois, pelo International Banking Facilities (IBF) nos EUA (1981), o Japanese Offshore MarketJOM (1986), o Bangkok International Bank Facility na Tailândia, Bahrein etc. (Palan, 2012). Aqui, deve-se acrescentar a cidade de Hong Kong, antiga colônia britânica e centro financeiro offshore, devolvida à China em 1997, porém mantida como CFO pelo governo chinês, como parte da política "um país, dois sistemas". Não há estatísticas oficiais sobre o movimento de dinheiro administrado pelos bancos e outras instituições financeiras em CFO. Palan (2012) se refere às estimativas de que um terço dos bancos internacionais dos EUA são regidos pelos IBF, e a metade dos japoneses pelo JOM, porém não os identifica como paraísos fiscais, mas como "refúgios regulatórios", uma feliz expressão, pois são livres de regulamentação mesmo quando sujeitos a cobrança de impostos. 
Dezesseis anos depois, o pequeno estado de Delaware, na costa leste dos EUA, idealizou e aprovou uma forma mais elaborada de legislação que se tornou o modelo para as LLC. Uma LLC permite, de forma combinada, a proteção dos ativos e limitação de responsabilidades pessoais dos membros/sócios da corporação, além de tratamento fiscal favorável aprovado pelas autoridades fiscais federais. $\bigcirc$ Delaware LLC Act (1993) permite, além disso, uma grande flexibilidade nos acordos internos da corporação, cada uma podendo desenhar a estrutura e as regras mais adequadas aos interesses dos seus membros. Mais de 60\% das 500 maiores companhias estadunidenses (uma lista anual elaborada pela revista Fortune) são incorporadas em Delaware, bastando uma sala e uma caixa de correio, entre elas, Bank of America (Bofa), Berkshire Hathaway, Cargill, Coca-Cola, General Electric, JPMorgan Chase, Walmart. Além dessas grandes corporações, pequenos negócios, alguns de origem duvidosa, aproveitam-se dessas facilidades para criar empresas fantasmas (shell companies) (Wayne, 2012).

A multiplicação de "refúgios regulatórios" retroalimenta o sistema financeiro e o sistema corporativo com dinheiro "livre" das exigências instituídas pelas autoridades monetárias nacionais e de organizações bancárias internacionais como o FMI e o Banco Mundial, o que amplia a disponibilidade de capital e de dinheiro para empréstimos e investimentos em qualquer lugar do mundo, inclusive nos territórios que hospedam esses "refúgios". Esse é um dos principais motivos para a relutância da maioria dos países em criticar ou mesmo mencionar esses "refúgios", apesar do papel que eles têm há décadas como facilitadores de operações interbancárias transnacionais, empréstimos, fuga de capitais ou lavagem de dinheiro (o critério para diferenciar os dois últimos é a origem do dinheiro, se proveniente de atividades consideradas criminosas pelas leis públicas de um estado ou não).

No caso do Brasil, por exemplo, os dados registram que entre as cinco "economias" que mais recebem investimentos diretos oriundos do país estavam a Áustria, as Ilhas Cayman, a Holanda, as Ilhas Virgens Britânicas e os EUA (nessa ordem) em 2011; o quadro apresenta ligeiras alterações em 2014 (Ilhas Cayman, Áustria, Ilhas Virgens Britânicas, Bahamas e Luxemburgo), segundo as estatísticas enviadas pelo Banco Central para a base de dados do CDIS-FMI.

A base de dados do CDIS-FMI também registra que entre as 10 maiores economias do mundo (2014), a origem dos investimentos diretos é proveniente, entre outros, da Holanda, de Luxemburgo, da China/Hong Kong, da Grã-Bretanha, de Singapura e da Suíça. $\bigcirc$ fluxo de investimento externo do pequeno Luxemburgo em 2014 era de 2,3 trilhões de dólares, equivalente ao PIB brasileiro no mesmo ano. São dinheiros em permanente "passagem" -extraterritoriais em relação ao lugar de origem, porém absolutamente legais em termos do lugar de registro e de desenvolvimento de suas operações. Das 500 corporações listadas pela revista estadunidense Fortune em 2014, pelo menos 358 operam um total de 7.622 subsidiárias localizadas em paraísos fiscais e centros financeiros offshore, acumulando 2,1 trilhão de dólares em lucros offshore, com destaque para as tecnológicas e as farmacêuticas (Figura 1). 


\section{Figura 1 - As 15 maiores corporações internacionais Montante em Offshore e número de subsidiárias localizadas em paraísos fiscais (dez. 2014)}

\begin{tabular}{|l|l|l|}
\hline companhia & $\begin{array}{l}\text { montante em offshore } \\
\text { (U\$ milhões) }\end{array}$ & $\begin{array}{l}\text { número de } \\
\text { subsidiárias em } \\
\text { paraísos fiscais }\end{array}$ \\
\hline Apple & 181.100 & 3 \\
\hline General Eletric & 119.000 & 18 \\
\hline Microsoft & 108.300 & 5 \\
\hline Pfizer & 74.000 & 151 \\
\hline International Business Machines & 61.400 & 15 \\
\hline Merck & 60.000 & 121 \\
\hline Johnson E Johnson & 53.400 & 58 \\
\hline Cisco Systems & 52.700 & 59 \\
\hline Exxon Mobil & 51.000 & 37 \\
\hline Google & 47.400 & 2 \\
\hline Procter E Gamble & 45.000 & 38 \\
\hline Citigroup & 43.800 & 41 \\
\hline Hewlett-Packard & 42.900 & 25 \\
\hline Oracle & 38.000 & 5 \\
\hline PepsiCo & 37.800 & 132 \\
\hline
\end{tabular}

fonte: McIntyre, Phillips e Baxandall (2015).

caso da Google é interessante: moveu várias patentes tecnológicas para a Irlanda, (sede das suas operações na Europa, Oriente Médio e África) de modo a aproveitar as regras que o Estado irlandês estabeleceu para atrair investimentos de companhias transnacionais no país; as subsidiárias irlandesas (que usam as patentes) estão registradas nas ilhas Bermuda (protetorado inglês no Caribe), o que permitiu a companhia não pagar impostos sobre os lucros auferidos sobre o uso das patentes por suas subsidiárias irlandesas. Em 2015, depois de um longo processo de negociação, a Google concordou em pagar 195,5 milhões de dólares em impostos passados às autoridades fiscais da Grã-Bretanha, o segundo maior mercado da Google depois dos EUA, com lucros estimados de 6,5 bilhões de dólares em 2014 . $\bigcirc$ pleito britânico se baseou na revelação de que a holding Google Holanda, que não tem empregados, pagou royalties no valor de 12 bilhões de dólares para a holding Google Irlanda em 2014 e 10 bilhões em 2013, sobre os quais não pagou imposto nem na Irlanda nem na Holanda (McIntyre; Phillips; Baxandall, 2015). Mais uma vez ressalta-se que todas essas operações não configuram "evasão fiscal", são legais, uma vez que permitidas pelos Estados nacionais ou protetorados hospedeiros; por esse motivo são denominadas pelo eufemismo "tax avoidance", ou seja, "evitar impostos".

Paralelamente, a Google desenvolveu uma inovação que envolve diretamente os conceitos de jurisdição, território e soberania. Em 2009, o escritório de patentes e marcas do governo central estadunidense the outorgou a patente de server farms (cluster de computadores poderosos 
conectados em rede) localizados em navios-plataforma no oceano e alimentados por água e energia eólica, com o que, argumentou a companhia, seu acesso às regiões do globo que necessitam de seus serviços será facilitado (Swanson, 2011). A possibilidade de futuras server farms maciças, povoando o oceano fora do alcance das jurisdições nacionais, está diretamente relacionada ao direito internacional e à jurisprudência da extraterritorialidade (Swanson, 2011, p. 722).

A "lei de liberdade de navegação dos oceanos" adotada no século XVII pelas potências coloniais do norte europeu para garantir o comércio marítimo irrestrito e a conexão com suas colônias espalhadas pelo globo foi posteriormente aceita por todas as nações e legitimada pelo direito internacional, ${ }^{12}$ porém agora esse mesmo princípio está posto em questão, na medida em que um país resolve tomar para si o poder de regulamentar o uso do espaço oceânico fora de suas fronteiras. ${ }^{13}$ Como Steven Swanson sugere, em futuro próximo existe a possibilidade de um navio server oferecer serviços bancários e financeiros sem pagamento de impostos, ou armazenar informações sobre a segurança nacional relacionadas aos interesses nacionais soberanos.

A noção de extraterritorialidade, quando aplicada ao mundo financeiro-corporativo, não significa que a globalização das redes financeiras anuncia o começo do fim do sistema de Estados territoriais nacionais. Ao contrário, é precisamente a condição de existência de limites políticos e jurisdicionais que permite sua manipulação por redes financeiras e corporativas. Não é por acaso que os debates mais interessantes sobre a relação entre política e economia se dão hoje no campo do direito internacional. Diante da vastidão e complexidade desse campo, bem acima dos conhecimentos da autora deste texto, nos limitaremos a tocar em um dos seus aspectos, o binômio legal-ilegal, ao qual nos referimos ao longo do texto e com o qual nos defrontamos anteriormente no trato da geografia do tráfico de drogas ilícitas, da lavagem de dinheiro e dos circuitos regionais transfronteiriços (Machado, 1996, 2009).

\section{A regra da lei e a regra do jogo: o binômio legal-ilegal}

Como discutido no decorrer deste artigo, a mais notória motivação das grandes corporações transnacionais para participar e sustentar esse jogo de arranjos jurisdicionais e territoriais é evitar leis fiscais e regulatórias dos diferentes Estados nacionais que possam limitar seus lucros e sua liberdade de ação. $\bigcirc$ jogo permite agradar aos acionistas e disponibiliza mais recursos para ampliar seu poder de investimento e o alcance geográfico de suas operações. Este último aspecto é essencial, pois quanto maior o número de usuários, maior é a legitimidade do sistema que permite a comunicação e o acesso a informações, sem que nós, os usuários, tenhamos noção do custo e do poder da imensa infraestrutura tecnológica que os sustenta, ou mesmo que elas possam ter um custo quando acessamos uma plataforma de acesso à internet "de graça". Tampouco temos noção do envolvimento de diversos tipos de manipulações sobre o que é legal ou ilegal no campo do direito, nem de suas consequências sobre o território, que remete ao campo da política.

12 A mesma questão jurisdicional extraterritorial e suas implicações nos campos do direito, nacional e internacional, é encontrada no atual debate sobre a regulamentação (ou não) do uso do ciberespaço (ver Hildebrandt (2016) e Johnson e Post (1996]).

13 Uma ação similar é a criação de ilhas artificiais pelo Estado chinês no Mar do Sul da China, sobre as quais exerce soberania fora de suas "águas territoriais" fazendo uso do princípio de extraterritorialidade. 
A extraterritorialidade permite que indivíduos e corporações contornem de forma legal as leis válidas em um território nacional por meio, por exemplo, de uma simples mudança do endereço postal (localização), uma vez que sua "presença" física foi tornada irrelevante por obra e graça de outra "ordem legal" que assim o determina. Para qualificar o comportamento humano como legal ou ilegal, a norma tem sido obedecer ou desobedecer à regra da lei, o que depende da instituição de diversos tipos de limites - espaciais, temporais, materiais e subjetivos - sem os quais não é possível estabelecer a ordem legal (Lindahl, 2010).

Diante do embate e, em muitos casos, sobreposição entre a ordem legal do sistema de Estados nacionais e a ordem legal em que opera a globalização (lex mercatoria, OMC, International Investment Law and Policy Regime - leis nacionais sobre competição entre empresas que são aplicadas em outros países, ou seja, extraterritorialmente), ${ }^{14}$ onde traçar o limite? Filósofo do direito, Hans Lindahl acena para a possibilidade da pluralidade política - manifesta em comportamentos que resistem à distinção entre legal e ilegal - ser representada por uma ordem do direito positivo denominada a-legalidade. ${ }^{15}$ Seria um tipo de comportamento sugestivo de outra possível ordem legal, que abrangeria os comportamentos que questionam (e dificultam) a distinção entre legal e ilegal num mundo globalizado, ${ }^{16}$ o que não seria uma novidade, se considerada a coexistência, desde sempre, de várias ordens legais num dado contexto sociotemporal. A proposta de Lindahl tem sido intensamente debatida, entre outros, por Martin Loughlin, quando observa que a ordem "legal" de uma corporação transnacional não se "sobrepõe" à lei de um Estado, ao permanecer dependente de sua autoridade para se tornar válida; para este autor, o debate não é tanto sobre o legal e o ilegal, mas sobre as condições de legitimidade da lei do Estado (Loughlin, 2014, p. 967 et seq.).

A abordagem de Lindahl levanta o problema conceitual da diferença (ou não) entre "de-territorialização" e "de-localização" no campo do direito. Gunther Teubner (1997) propõe a indiferenciação entre os dois conceitos sob a justificativa de que as formas globais de autorregulação privada (como a das multinacionais ou como a lex mercatoria, a lei transnacional sobre transações econômicas, que seria um exemplo bem-sucedido de uma lei global sem Estado) são válidas por ser de-localizadas, tornando-se leis globais, irredutíveis à organização territorial de um Estado-nação. A essa proposta, Lindahl contrapõe a seguinte questão: não haverá um sentido mais fundamental, no qual mesmo uma lei global deve ser espacialmente delimitada, localizada? (Lindahl, 2010, p. 31). Em suma, o autor afirma que a a-legalidade aponta para a forma primordial de delimitação espacial constitutiva de todas as ordens legais - a distinção do que está "dentro" e o que está "fora". Nesse sentido fundamental, todas as ordens legais são localizadas, ou seja, estão inseridas em determinado contexto.

14 Sobre nações ou corporações afetadas pela aplicação de leis, elaboradas em outras nações, que violam sua própria soberania nacional, ver Falvey e Lloyd (1999). Para uma discussão sobre o papel político desse tipo de leis na mundialização, ver Anderson (2013) e Scott e Ambler (2007).

15 Lindahl se inspira e adota parcialmente o termo de Carl Schmitt (ver Minkkinen [2016]).

16 Um dos exemplos de Lindahl é o movimento pela reforma agrária no Brasil, promovido pelo MST, ao ocupar terras improdutivas para estabelecer cooperativas agrícolas e habitacionais. Para o autor, as ações de ocupar escritórios de instituições públicas, multinacionais ou bloquear estradas também são manifestações de a-legalidade. 
Se for aceita a indistinção entre localização e territorialização, como propõe Teubner, as teorias sobre leis globais tenderão a esconder - e com isso despolitizar - a delimitação espacial dessas ordens legais: a re-politização da espacialidade de ordens legais globais nos obriga a atentar para os limites espaciais como objeto de contestação (Lindahl, 2010, p. 31). Em síntese, o comportamento é legal ou ilegal em referência ao lugar, se está fora ou no lugar, se atua no momento certo ou não, se exercita direitos e obrigações como estabelecidas por lei, ou não. Em todas essas situações, a decisão é de ordem política.

\section{Referências}

AGAMBEN, G. The Signature of all things: On Method. Brooklyn, EUA: Zone Books, 2009.

State of Exception. Chicago: University Chicago Press, 2005.

ANDERSON, P. Imperium. New Left Review, n. 83, Londres, p. 5-111, set./out. 2013.

BAUMAN, Z. The world inhospitable to Levinas. Philosophy Today, v. 43, n. 2, p. 151-67, 1999.

BRYAN, D.; RAFFERTY, M.; WIGAN, D. Capital unchained: finance, intangible assets and the double life of capital in the offshore world. Review of International Political Economy, v. 24, n. 1, p. 56-86, 2017.

CAMERON, A. Where has all the (xeno)money gone? In: AMIR, M.; SELA, R. (Ed.). Extraterritorialities in occupied worlds. [s.1.]: Punctum Books, 2016. p. 117-155.

CASTELLS, M. The Information Age: Economy, Society and Culture. Malden: Blackwell, 1998[1996]. v. 3.

CUTLER, A. C. Artifice, ideology and paradox: the public/private distinction in international law. Review of International Political Economy, v. 4, n. 2, p. 261-285, 1997.

FALVEY, R.; LLOYD, P. J. An economic analysis of extraterritoriality. Melbourne Dept. Economics, Paper 675, p. 1-22, 1999.

FOUCAULT, M. Segurança, território, população. São Paulo: Martins Fontes, 2008.

FRANKE, A.; WEIZMAN, E.; WEIZMAN, I. Islands: The geography of extraterritoriality. Archis, Amsterdã, v. 6, p. 18-54, 2003.

GALLI, C. Political Spaces and Global War. Minneapolis, EUA: University of Minnesota Press, 2010.

GROVOGUI, S. N. Regimes of Sovereignty: International Morality and the African Condition. European Journal of International Relations, v. 8, n. 3, p. 315-338, 2002.

HART, K. The informalization of the world economy. In: CONFERENCE OFTHE SOCIETA'ITALIANA DI ECONOMIA PUBBLICA, 24. - Informal economy, tax evasion and corruption, 24-25 set. 2012, Pavia. Anais... Pavia, 2012.

HENRY, J. S. The Price of Offshore Revisited. [s.1]: TJN, 2012. 
HILDEBRANDT, M. Extraterritorial Jurisdiction to Enforce in Cyberspace? Bodin, Schmitt, Grotius in Cyberspace. In: AMIR, M.; SELA, R. Extraterritorialities in Occupied Worlds. [s.l.]: Punctum Books, 2016. p. 173-202.

HOUSE of Commons. Treasury Committee. Offshore Financial Centres. Written Evidence. London: House of Commons, 2008.

IMF. INTERNATIONAL MONETARY FUND. The Coordinated Direct Investment Survey (CDIS). Washington, DC: IMF, 2015a.

The Coordinated Direct Investment Survey Guide. Pre-Publication Draft. Washington, DC: IMF, 2015b.

Balance of Payments and International Investment Position Manuel (BPM6). 6th. ed. Washington, DC: IMF, 2009.

JOHNSON, D.; POST, D. Law and Borders-The rise of law in cyberspace. Stanford Law Review, v. 48, n. 5, p. 1367-1402, 1996.

KRATOCHWILL, F. Of Maps, Law and Politics: an inquiry into the changing meaning of territoriality. DIIS Working Paper 2011, p. 1-26, 2011.

LINDAHL, H. A-Legality: Post-nationalism and the question of legal boundaries. The Modern Law Review, v. 73, n. 1, p. 30-56, 2010.

LUQUE, C.; SILBER, S.; ZAGHA, R. Fim de três ilusões sobre o investimento externo direto. Valor Econômico, 20 fev. 2017. Opinião.

LOUGHLIN, M. A-Legality or Jus Politicum? A critical appraisal of Lindahl's Fault Lines of Globalization. Ethics \& Politics, v. XVI, n. 2, p. 965-972, 2014.

MACHADO, L. O. Ambiguidade entre o legal e o ilegal: redes de tráfico de drogas ilícitas e território. In: CHÁVEZ TORRES, M.; CHECA ARTASU, M. (Ed.). El Espacio en las Ciencias Sociales: Geografía, interdisciplinariedad y compromiso. Zamora, MX: El Colegio de Michoacán, 2013. p. 315-329. v. 1.

Ambiguidade entre o legal e o ilegal: redes de tráfico de drogas ilícitas e território. In: COLOQUIO DE ANTROPOLOGÍA E HISTORIA REGIONALES, 31., 2009, Zamora, MX. Anais... Zamora, MEX, out. 2009.

. comércio ilícito de drogas e a geografia da integração financeira: uma simbiose? In: CASTRO, I. E. et al. Brasil: questões atuais da reorganização do território. Rio de Janeiro: Bertrand Brasil, 1996. p. 15-64.

McINTYRE, R. S.; PHILLIPS, R.; BAXANDALL, P. Offshore Shell Games 2015: The use of Offshore Tax Havens by Fortune 500 Companies. U.S. PIRG Education Fund and Citizens for Tax Justice, 2015. Disponível em: http://ctj.org/ctjreports/2015/10/offshore_shell_games_2015.php\#.WadYFciGOUk. Acesso em: 8 jul. 2017.

MICHAELS, R. The True Lex Mercatoria: Law Beyond the State. Indiana Journal of Global Legal Studies, v. 14, n. 2, p. 447-468, 2007. 
MignOLO, W. The Prospect of Harmony and the Decolonial View of the

World: Weihua He interviews. 12 jun. 2014. Disponível em: http://criticallegalthinking.com/2014/06/12/prospect-harmony-decolonial-view-mignolo/. Acesso em: 8 jul. 2017.

Local Histories/Global Designs: Coloniality, Subaltern Knowledges, and Border Thinking. Princeton: Princeton University Press, 2012[2000].

MINKKINEN, P. A-legal irruptions and spatial revolutions. Jurisprudence, v. 7, n. 1, p. 1-11, 2016.

PALAN, R. Tax Havens and Offshore Financial Centres. Academic Foresights, n. 4, p. 1-15, abr./jun. 2012.

. Tax Havens and the Commercialization of State Sovereignty. International Organization, v. 56, n. 1, p. 151-176, 2002.

QUIJANO, A. Cuestiones y horizontes. Antología esencial: de la dependencia históricoestructural a la colonialidad/descolonialidad del poder. Buenos Aires: Clacso, 2014.

SCOTT, S.; AMBLER, O. Does Legality Really Matter? Accounting for the Decline in US Foreign Policy Legitimacy Following the 2003 Invasion of Iraq. European Journal of International Relations, v. 13, p. 67-87, 2007.

SWANSON, S. R. Google sets sail: Ocean-based server farms and international law. Conneticut Law Review, v. 43, n. 3, p. 711-751, 2011.

TEUBNER, G. Global Bukowina: Legal Pluralism in the World Society. In: TEUBNER, G. (Ed.). Global Law without a state. Dartmouth: Aldershotm, 1997. p. 3-38.

WAYNE, L. How Delaware Thrives as a Corporate Tax Haven. New York Times, New York, 30 jun. 2012.

WEIZMAN, E. On Extraterritoriality. Conference lectured. In: SYMPOSIUM ARCHIPELAGO OF EXCEPTION. SOVEREIGNTIES OF EXTRATERRITORIALITY, 2005, Barcelona. Anais... Barcelona, 10-11 nov. 2005. Disponível em: http://www.publicspace.org/en/text-library/eng/b011-on-extraterritoriality. Acesso em: 12 ago. 2017. 